Volume 8. No. 5, May 2020

International Journal of Emerging Trends in Engineering Research

Available Online at http://www.warse.org/IJETER/static/pdf/file/ijeter09852020.pdf

https://doi.org/10.30534/ijeter/2020/09852020

\title{
Calculation of metallurgical processes during welding
}

\author{
Smirnova Zhanna. ${ }^{1}$, Vaganova O.I. ${ }^{2}$, Chaykina Zh. V $^{3}$, Golubeva O.V ${ }^{4}$. \\ ${ }^{1}$ Minin Nizhny Novgorod State Pedagogical University, Nizhny Novgorod, Russian Federation \\ z.v.smirnova@mininuniver.ru \\ ${ }^{2}$ Minin Nizhny Novgorod State Pedagogical University (Minin University), Nizhny Novgorod, \\ Russian Federation, vaganova_o@mail.ru \\ ${ }^{3}$ Minin Nizhny Novgorod State Pedagogical University (Minin University), Nizhny Novgorod, Russian \\ Federation, jannachaykina@mail.ru \\ ${ }^{4}$ Minin Nizhny Novgorod State Pedagogical University (Minin University), Nizhny Novgorod, \\ Russian Federation, gololga@yandex.ru
}

\begin{abstract}
The article considers the metallurgical process during welding of materials. A study and description of the physicochemical processes of the interaction of metal with gas and slag is carried out. The process of heating, melting and cooling the base metal during welding is calculated. The process of crystallization of a metal during the formation of a welded joint is studied and described. Researched Steel 30XMA. After the calculation study, a conclusion was drawn on the structure and properties of the sections of the base metal adjacent to the seam.
\end{abstract}

Key words: metallurgical process, weldability of metal, steel, crystallization of metal

\section{INTRODUCTION}

By its nature, arc welding by melting is a metallurgical process. Metallurgical processes are understood as high-temperature processes of interaction of liquid metal with gases and welding slags, as well as solidifying metal with liquid and crystallizing slags.

These processes occur during the electrode melting, the transition of liquid metal through the arc gap and in the welding bath itself $[2,3]$.

In contrast to the metallurgical processes occurring in conventional steelmaking furnaces, the welding process has some features. The acquisition of skills in theoretical and experimental research of welding processes and the search to control these processes to obtain high-quality welded joints [1].

The main aims of the study are:

- research and description of physical and chemical

processes of metal interaction with gas and slag;

- research the heating, melting and cooling processes of the base metal during welding;
- study and description of metal crystallization processes in the formation of a welded joint;

- development of ways to increase the technological strength in the process of crystallization of the weld and the joint's cooling.

\section{LITERATURE REVIEW}

2.1 Basic parameters and constants of the metal to be welded

Steel 30CrMo belongs to medium-carbon low-alloy steels. The approximate chemical composition and main properties are shown in the tables below:

Table 1: Chemical composition of steel and main indicators

\begin{tabular}{|c|c|c|c|c|c|c|c|}
\hline $\mathrm{C}$ & $\mathrm{Mn}$ & $\mathrm{Si}$ & $\mathrm{P}$ & $\mathrm{S}$ & $\mathrm{Cr}$ & $\mathrm{Ni}$ & $\mathrm{Cu}$ \\
\hline $0,26-$ & 0,40 & $0,17-$ & $\leq$ & $\leq$ & $0,8-$ & & \\
0,33 & $-0,7$ & 0,37 & 0,025 & 0,02 & 1,1 & 0,3 & 0,3 \\
\hline
\end{tabular}

Table 2: Main steel properties

\begin{tabular}{|c|c|c|c|c|}
\hline$\Delta \omega$ опт, deg/sec & $\mathrm{A}_{\mathrm{Cl}}$ & $\mathrm{A}_{\mathrm{C} 3}$ & $\mathrm{M}_{\mathrm{H}}$ & $\mathrm{T}_{\text {нир }}$ \\
\hline $0,1-10$ & 757 & 807 & 350 & 850 \\
\hline
\end{tabular}


Smirnova Zhanna.V et al., International Journal of Emerging Trends in Engineering Research, 8(5), May 2020, $1529-1534$

Table 3: Thermal constants

\begin{tabular}{|l|l|}
\hline$\lambda$ - thermal conductivity & $41.9 \mathrm{~W} / \mathrm{m} \cdot \mathrm{deg}$ \\
\hline $\begin{array}{l}\text { a - temperature } \\
\text { conductivity }\end{array}$ & $8.7 \cdot 10^{-6} \mathrm{~W} / \mathrm{m}^{2} \mathrm{deg}$ \\
\hline c $\rho$ - volume heat capacity & $4.8 \mathrm{~J} / \mathrm{m}^{3} \cdot \mathrm{deg}$ \\
\hline$\alpha$ - heat transfer coefficient & $60 \mathrm{~m}^{2} / \mathrm{sec}$ \\
\hline
\end{tabular}

\subsection{Structure and properties of the metal to be welded}

The studied steel $30 \mathrm{CrMo}$ is characterized by a pronounced irregularity of sulfur and phosphorus spread in the thickness of rolled products. Local high concentration of sulfur can lead to the formation of crystallization cracks in the seam and near-seam zone. [4].The introduction of a small amount of copper $(0.3-0.4 \%)$ into low-alloy steels increases the steel's resistance to corrosion (atmospheric and seawater). For the manufacture of welded structures, low-alloy steels are used in the hot-rolled state. The alloying elements introduced into steel $30 \mathrm{CrMo}$, forming with iron, carbon and other elements solid solutions and chemical compounds that alter its properties [5]. This increases the mechanical properties of steel and, in particular, reduces the transition temperature. As a result, it is possible to reduce the weight of structures. In industry, medium-carbon, low-alloy steels are widely used in the production of welded structures. The total content of alloying elements in these steels does not exceed $4.0 \%$ (not counting carbon), and carbon $0.3 \%$.

Table 4: Mechanical properties of 30CrMo steel:

\begin{tabular}{|c|c|c|c|}
\hline \multicolumn{4}{|c|}{ Mechanical properties } \\
\hline $\begin{array}{c}\text { Resistance to } \\
\text { rupture, } \\
\mathrm{MPa}\end{array}$ & $\begin{array}{c}\text { Flow limit, } \\
\mathrm{MPa}\end{array}$ & $\delta, \%$ & $\square, \%$ \\
\hline 800 & 600 & 12 & 50 \\
\hline
\end{tabular}

\subsection{Assessment of metal weldability}

Steel $30 \mathrm{CrMo}$ has a limited weldability. Its welding technology should provide a certain set of requirements, the main of which are equal strength of the welded joint with the base metal and the soundness in the weld. To do this, the mechanical properties of the seam metal and the near-seam zone must not be lower than the lower limit of the mechanical properties of the base metal. In some cases, the specific operating conditions of structures allow reducing certain indicators of mechanical properties of the welded joint. However, in most cases, especially when welding critical structures, the seams should not have cracks, bad welding, pores, rolled kinks. [6,7]. The geometric dimensions and joint shape must meet the required requirements. The welded joint must be resistant against the transition to the brittle state. In some cases, additional requirements are imposed on the welded joint (performance under vibration and shock loads, low temperatures, etc.). However, in all cases, the technology must ensure maximum productivity and cost-effectiveness of the welding process with the required reliability and durability of the structure.

The mechanical properties of the weld metal and the weld joint depend on its structure, which is determined by the chemical composition, welding mode and previous and subsequent heat treatment. When welding the steel, the seam metal differs slightly from the base metal. There is less carbon in the seam metal to prevent quenching structures at higher cooling rates. A possible reduction in the strength of the seam metal caused by a decrease in the carbon is compensated by alloying the metal through a wire, coating or flux with manganese and silicon [8].

Increased cooling rates of the seam metal help to increase its strength, but at the same time reduce the plastic properties and impact strength. The rate of cooling of the weld metal is determined by the thickness of the metal being welded, the design of the weld joint, the welding mode and the initial temperature of the product.

Heating and subsequent heat treatment are recommended. Welding methods: electrode welding, argon arc electrode welding, quasi-arc welding, resistance-welding.

\section{RESULTS AND DISCUSSIONS}

During the research the technological stage of steel $30 \mathrm{CrMo}$ weldability was carried out.

Reaction under study:

$$
\mathrm{Na}+\mathrm{F}=\mathrm{NaF}
$$

The probability of a reaction behavior at a given temperature is determined by the formula:

$$
\begin{gathered}
\Delta \mathrm{G}_{\mathrm{T}}^{\mathrm{o}}=\Delta \mathrm{H}^{\mathrm{o}}{ }_{298}-\Delta \mathrm{S}_{298}^{\mathrm{o}} \mathrm{T}-\Delta \mathrm{C}^{\mathrm{o}} \mathrm{p}_{298} \mathrm{f}(\mathrm{T}) \mathrm{T} \\
\text { where } \Delta \mathrm{gt}^{\mathrm{o}} \text {-Gibbs function, } \mathrm{kJ} / \mathrm{mol} \\
\Delta \mathrm{H}^{\circ} 298 \text {-enthalpy, } \mathrm{kJ} / \mathrm{mol} \\
\Delta \mathrm{S}^{\mathrm{o}} 298 \text {-entropy, } \mathrm{J} / \mathrm{mol} \mathrm{K} \\
\Delta \mathrm{C}^{\mathrm{o}} \mathrm{p} 298 \text {-heat capacity, } \mathrm{J} / \mathrm{mol} \mathrm{K} \\
\mathrm{F}(\mathrm{T}) \text { - Ulich function } \\
\mathrm{T}-\text { absolute temperature, } \mathrm{K}
\end{gathered}
$$

Formula for calculating the enthalpy:

$$
\Delta \mathrm{H}_{298}^{\mathrm{o}}=\Sigma \Delta \mathrm{H}_{\mathrm{r}}^{\mathrm{o}}-\Sigma \Delta \mathrm{H}_{\text {ref }}^{\mathrm{o}}=\Delta \mathrm{H}_{\mathrm{NaF}}^{\mathrm{o}}-\left(\Delta \mathrm{H}_{\mathrm{Na}}^{\mathrm{o}}+\Delta \mathrm{H}_{\mathrm{F}}^{\mathrm{o}}\right)
$$

Formula for calculating entropy:

$$
\Delta \mathrm{S}_{298}^{\mathrm{o}}=\Sigma \Delta \mathrm{S}_{\mathrm{r}}^{\mathrm{o}}+\Sigma \Delta \mathrm{S}_{\text {ref }}^{\mathrm{o}}=\Delta \mathrm{S}_{\mathrm{NaF}}^{\mathrm{o}}-\left(\Delta \mathrm{S}_{\mathrm{Na}}^{\mathrm{o}}+\Delta \mathrm{S}_{\mathrm{F}}^{\mathrm{o}}\right)
$$

Formula for calculating the heat capacity:

$$
\Delta \mathrm{Cp}_{298}^{\mathrm{o}}=\Sigma \Delta \mathrm{Cp}_{\mathrm{r}}^{\mathrm{o}}+\Sigma \Delta \mathrm{Cp}_{\text {ref }}^{\mathrm{o}}=\Delta \mathrm{Cp}_{\mathrm{NaF}}^{\mathrm{o}}-\left(\Delta \mathrm{Cp}_{\mathrm{Na}}^{\mathrm{o}}+\Delta \mathrm{Cp}_{\mathrm{F}}^{\mathrm{o}}\right)
$$

The data is shown in a table:

Table 5: Basic data:

\begin{tabular}{|c|c|c|c|}
\hline Substance & $\begin{array}{c}\Delta \mathrm{H}^{\mathrm{o}}{ }_{298,} \\
\mathrm{~kJ} / \mathrm{mol}\end{array}$ & $\begin{array}{c}\Delta \mathrm{S}^{\mathrm{o}}{ }_{298,}, \\
\mathrm{~J} / \mathrm{mol} \mathrm{K}\end{array}$ & $\begin{array}{c}\Delta \mathrm{Cp}^{\mathrm{o}}{ }_{298,}, \\
\mathrm{~J} / \mathrm{mol}^{\mathrm{K}} \mathrm{K}\end{array}$ \\
\hline $\mathrm{NaF}$ & -573.6 & 51.3 & 46.82 \\
\hline $\mathrm{Na}$ & 0 & 51.45 & 28.16 \\
\hline $\mathrm{F}$ & 4.75 & 53.9432 & 7.8046 \\
\hline
\end{tabular}


Smirnova Zhanna.V et al., International Journal of Emerging Trends in Engineering Research, 8(5), May 2020, $1529-1534$

Ulich function is calculated using the formula:

$$
\mathrm{F}(\mathrm{T})=\ln (\mathrm{T} / 298)+298 / \mathrm{T}-1
$$

Calculate the numerical values of Ulich function for certain temperatures:

$\mathrm{f}(298)=0$

$\mathrm{f}(1000)=0.508662$

$\mathrm{f}(2000)=1.052809$

$\mathrm{f}(3000)=1.408607$

$\mathrm{f}(4000)=1.671456$

$\mathrm{f}(6000)=2.052088$

Find the numerical values $\Delta \mathrm{H}^{\mathrm{o}}{ }_{298}, \Delta \mathrm{S}_{298}^{\mathbf{o}}, \Delta \mathrm{Cp}^{\mathbf{o}}{ }_{298}, \Delta \mathrm{G}^{\mathbf{o}}{ }_{298}$ $\Delta \mathrm{H}_{298}^{\mathrm{o}}=(-573.6-(0+4,75))=-578,35 \mathrm{~kJ} / \mathrm{mol}$
$\Delta \mathrm{S}_{298}^{\mathrm{o}}=(51,3-(51,45+53,9432))=-54,09 \mathrm{~J} / \mathrm{mol} \mathrm{K}$

$\Delta \mathrm{Cp}^{\mathrm{o}}{ }_{298}=(46.82-(7.8046+28,16))=10,86 \mathrm{~J} / \mathrm{mol} \mathrm{K}$

Calculate Gibbs free energy $\Delta \mathrm{G}^{\circ} \mathrm{t}$ and the enthalpy $\Delta \mathrm{H}_{\mathrm{r}}$ for

temperatures

$298-6000 \mathrm{~K}$.

$$
\Delta \mathrm{G}_{\mathrm{T}}^{\mathrm{o}}=\Delta \mathrm{H}_{298}^{\mathrm{o}}-\Delta \mathrm{S}_{298}^{\mathrm{o}} \mathrm{T}-
$$

$\Delta \mathrm{C}^{\mathrm{o}} \mathrm{p}_{298} \mathrm{f}(\mathrm{T}) \mathrm{T}=-578350-(-54,09 \cdot 1000)-10,86 \cdot 0,508662 \cdot 1000$

$=-529,78 \mathrm{~kJ} / \mathrm{mol}$

$\Delta \mathrm{H}_{\mathrm{r}}=\Delta \mathrm{H}_{298}-\Delta \mathrm{Cp}_{298}(\mathrm{~T}-298), \mathrm{kJ} / \mathrm{mol}[9,14]$.

The results are presented in the table 6 :

Table 6: Calculation results

\begin{tabular}{|c|c|c|c|c|c|c|}
\hline $\mathrm{T}, \mathrm{K}$ & 298 & 1000 & 2000 & 3000 & 4000 & 6000 \\
\hline $\begin{array}{c}\Delta \mathrm{G}_{\mathrm{T}}^{\circ} \\
\mathrm{kJ} / \mathrm{mol}\end{array}$ & $-578,35$ & $-529,78$ & $-493,04$ & $-461,972$ & $-434,598$ & $-387,524$ \\
\hline$\Delta \mathrm{H}_{\mathrm{r}, \mathrm{kJ} / \mathrm{mol}}$ & $-642,8$ & -785 & -933 & -1078 & -1186 & -1411 \\
\hline
\end{tabular}

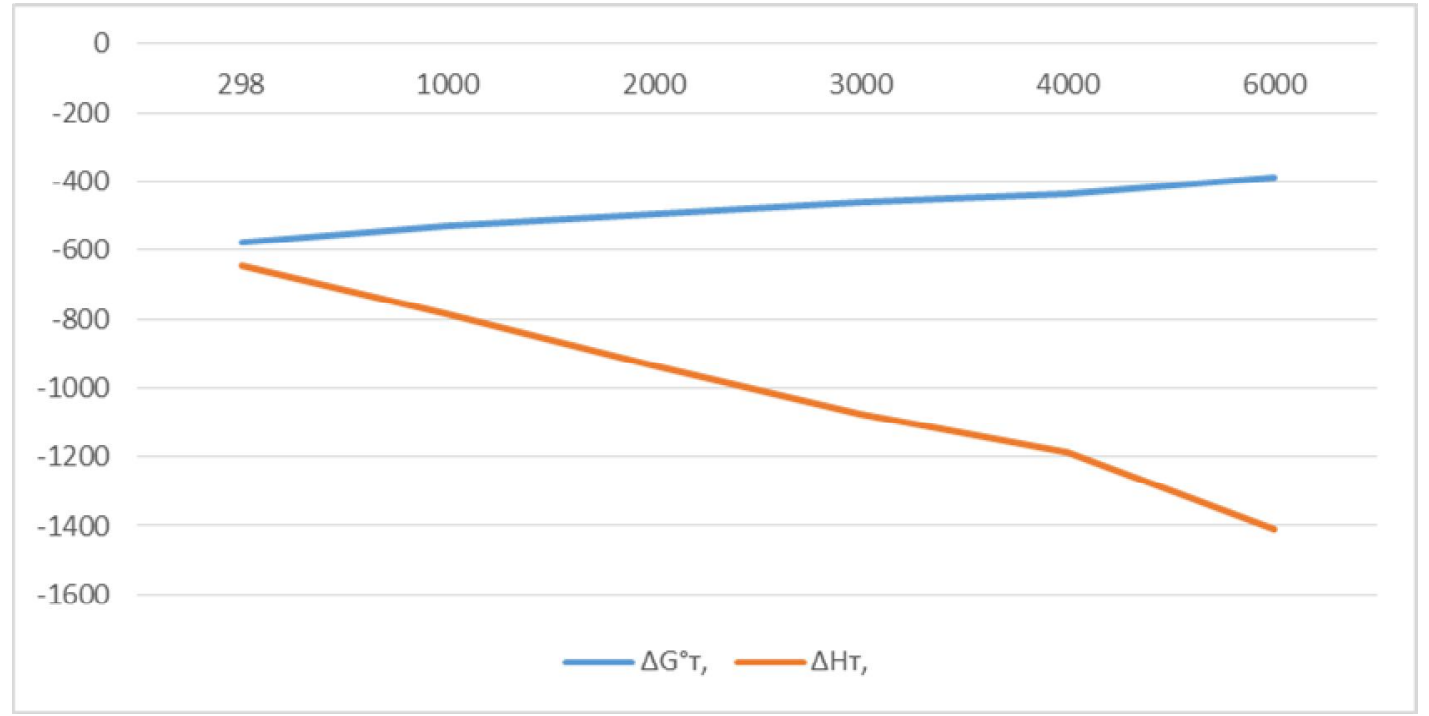

Figure 1: Gibbs thermodynamic potential graph

Thus, based on the calculation, we have obtained that $\Delta \mathrm{H}$ is negative. Therefore, the reaction proceeds with heat release. At standard temperature $\Delta \mathrm{G}$ is negative, which means that the reaction goes directly.

$$
T_{(R, X)}=\frac{q_{u}}{2 \pi \lambda \cdot \sqrt{x^{2}+y^{2}}} \cdot \exp \left(-\frac{V_{c b}}{2 a} \cdot\left(x+\sqrt{x^{2}+y^{2}}\right)\right)
$$

where $\mathrm{q}_{\mathrm{U}}$ is the linear energy transmitted by the source to the $q_{U}=U \cdot I \cdot \eta=28 \cdot 300 \cdot 0.75=6300 \mathrm{Bm}$.
Calculate the temperature distributions along the seam axis. The equation of the limit state of the heat allocation process for the PTI source has the form: body. It is calculated by the formula: 
To calculate the temperature distribution along the seam axis, we calculate $X$ in the range from $-20 \mathrm{~cm}$ to $40 \mathrm{~cm}$. [10,13]. The distribution is built on the seam axis $(\mathrm{y}=0)$, at the distance of 1 $\mathrm{cm}$ from the seam axis $(\mathrm{y}=1), 1.5 \mathrm{~cm}$ and $2 \mathrm{~cm}$. The distribution is presented below in figure 2 .
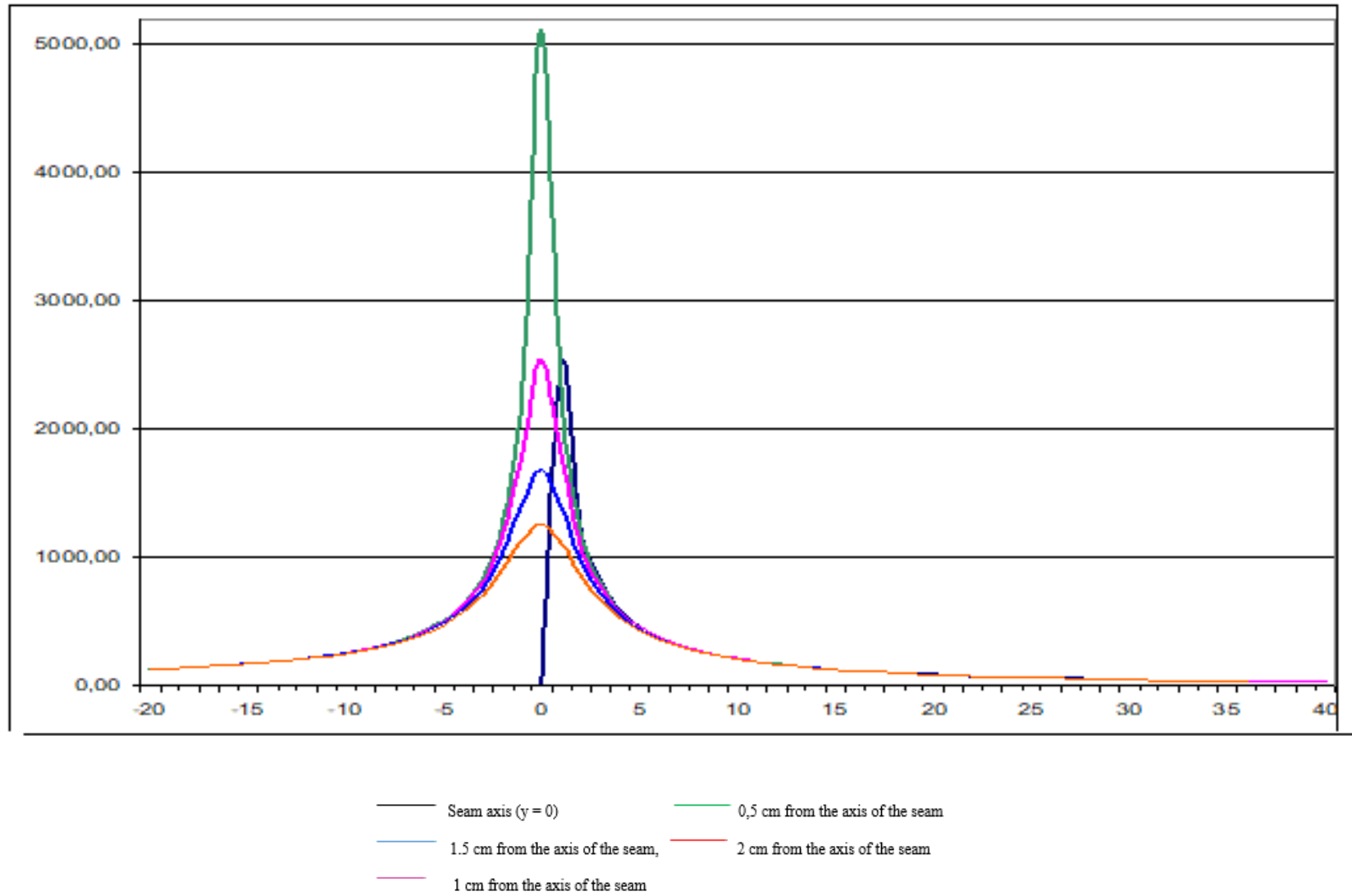

Figure 2: Temperature distribution along the seam axis

To calculate the length of some sections of the HAZ, it is necessary to plot a graph of maximum temperatures in the cross-section of the seam $[11,12]$.

To graph this, use the formula

$$
\Delta T_{\max }=\frac{q_{U}}{\sqrt{2 \pi e} \cdot V_{c b} \cdot c \rho \cdot \delta \cdot y_{0}}
$$

Tthe maximum temperatures distribution in the cross-section of the seam is shown below in figure 3 .

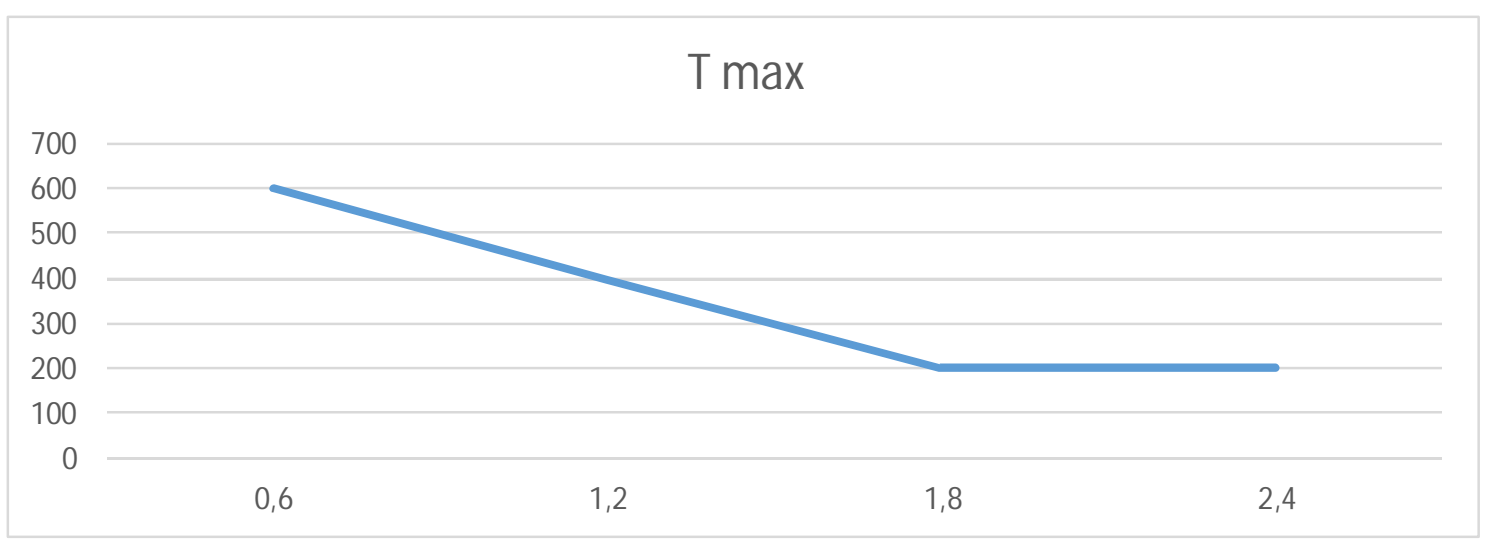

Figure 3: A graph of the maximum temperatures 
Smirnova Zhanna.V et al., International Journal of Emerging Trends in Engineering Research, 8(5), May 2020, $1529-1534$

The zones' widths with temperatures exceeding the typical temperatures are shown below in table 7:

Table 7: The zones' widths with temperatures

\begin{tabular}{|c|c|c|c|}
\hline & & \multicolumn{2}{|c|}{ Width } \\
\hline Tm & 1536 & 0,57 & Tm \\
\hline Tov & 1500 & 0,58 & Tov \\
\hline Tov2 & 1100 & 0,61 & Tnorm \\
\hline Tnorm & 905 & 0,78 & Tirec \\
\hline Tirec & 727 & 0,80 & Trec \\
\hline Trec & 450 & 0,94 & Tbl \\
\hline Tbl & 200 & 0,96 & \\
\hline
\end{tabular}

Here one can see that the widths of the corresponding zones is shown in table 8

Table 8: Widths of the corresponding Zones

\begin{tabular}{|c|c|}
\hline Width of the zone & $\mathrm{cm}$ \\
\hline Incomplete melting-down & 0,01 \\
\hline Overheating & 0,03 \\
\hline Normalizing & 0,17 \\
\hline Incomplete recrystallization & 0,02 \\
\hline Recrystallization & 0,14 \\
\hline Blue-shortness & 0,02 \\
\hline
\end{tabular}

\section{CONCLUSION}

During welding, the structure and properties of the base metal joining the seam change.

Heat affected zone (HAZ) is a section of the base metal joining the weld, the structure and properties of which change due to the heat effect of the welding energy source.

HAZ has several structural sections that differ in the shape and structure of the grain, depending on the heating temperature.

The part of incomplete melting is transition from the deposited metal to the main one. At this site, a joint is formed and the fusion boundary passes. It is a very narrow area of the base metal, heated below the liquidus line, but above the solidus line. In this zone, there is a significant growth of grains and contamination, thus this area is usually a weak point of the welded joint, having reduced strength and plasticity.

The hot spot area is the area of the base metal that is heated to the temperature of $1100 . .1500^{\circ} \mathrm{C}$. The metal of this section undergoes an allotropic transformation $\mathrm{Fe} \alpha \rightarrow \mathrm{Fe} \gamma$. The metal of this zone is characterized by a coarse-grained structure and reduced mechanical properties.

The normalizing area is the area of metal that is heated to the temperatures of $905-1100^{\circ} \mathrm{C}$. The metal of this section has high mechanical properties due to its fine-grained structure.

An incomplete recrystallization area is the zone where the metal is heated to $727-905^{\circ} \mathrm{C}$. Incomplete recrystallization of this area is due to lack of time and low heating temperature. The structure consists of small recrystallized and large grains.
Compared to the normalizing area, the mechanical properties are somewhat reduced.

A recrystallization area is the section of metal that is heated to a temperature of $380-727^{\circ} \mathrm{C}$. Recrystallization is a change in the structure of a deformed metal when it is heated above a

certain temperature. In this case, the distorted crystal structure turns into an non-tensioned one.

Irreversible temper brittleness (blue-shortness) is the heated metal up to $200-380^{\circ} \mathrm{C}$, transit between $\mathrm{HAZ}$ and the base metal. After some time, blue-shortness processes may occur due to the loss of iron carbides and nitrides. There are no noticeable structural changes.

Steel $30 \mathrm{CrMo}$ is limited to welding, but it is desirable to obtain the composition of the seam metal, close to the base metal. This steel can form hot and cold cracks, so there is a need for heating and subsequent heat treatment. Welding can be performed on both direct and alternating currents. This type of source corresponds to quasi-arc welding in one pass.

\section{REFERENCES}

1. Bykovsky Yu.A., Nevolin V.N., Fominsky V.Yu. Ion and laser implantation of metallic materials. - $\mathrm{M}$.: Energoatomizdat, 1991

2. Bagdasarova, T. A. Fundamentals of metal cutting / T.A. Bagdasarova. - M.: Academy, 2012.

3. Baimakov, Yu. V. Metallurgy of rare metals / Yu.V. Baimakov. - Moscow: Lights, 2012. 
4. Vedenov A.A., Gladush G.T. Physical processes during laser processing of materials. - M .: Energomashizdat, 1985

5. Grigoryants A.G., Safonov A.N. Surface laser treatment methods. Ser. Laser equipment and technology. - M $\therefore$ Higher. school., 1987.V.3.

6. Technological lasers: a Handbook. In 2 t. / Ed. G.A. Abilcia-tova. -M.: Engineering, 1991.V. 1

7. Mayorov V.S. The use of surface-active substances to change the nature of convection during laser doping // All-Union Conference on the Interaction of Optical Radiation with Matter. Leningrad, March 14-18. 1988 / L.: Metallurgizdat.

8. Mayorov V.S., Matrosov M.P. The effect of surface-active substances on the hydrodynamics of laser doping of metals // Quantum Electronics. T. 16. No. 4. 1986. S. 806-810.

9. A. P. Menushenkov, V. N. Nevolin, V. N. Petrovsky. Physical fundamentals of laser technology. M.: NRNU MEPhI, 2010,

10. Laser technology for processing materials: modern problems of basic research and applied development / Ed. V. Ya. Panchenko. - M.: Fizmatlit, 2009

11. Smirnova, Z.V., Rudenko, A.A., Vaganova, O.I., Cherney, O.T.,, Mokerov, D.S., Semakhin, E.A. The research of carbon construction steel at laser alloying //International Journal of Innovative Technology and Exploring Engineering 2019. 8(9), c. 2371-2375

https://doi.org/10.35940/ijitee.I8945.078919

12. Smirnova, Z.V., Vaganova, O.I., Cherney, O.T., Romanovskaya, E.V., Andryashina, N.S., Toshin, D.S. The organization of emergency and dispatching servicing of an apartment house// International Journal of Innovative
Technology and Exploring Engineering 8(9), 2019. c. 1477-1480

13. Smirnova, Z.V., Mukhina, M.V., Katkova, O.V., Gruzdeva, M.L., Chernei, O.T. Network Interaction as a Factor of Professional Qualities' Development of Service Workers//Lecture Notes in Networks and Systems, 87, pp. 698-704. International Journal of Innovative Technology

14. A.A. Sokolovsky1,2, A.I. Zemtsov3 , D.I. Kovalev4, E.M. Shishkov3,4, A.A. Kazantsev Hybrid Fiber Optic Temperature Sensor Powered by Optical Radiation, International Journal of Emerging Trends in Engineering Research Volume 7, No. 12 December 2019 https://doi.org/10.30534/ijeter/2019/217122019 